\title{
Memórias inventadas e vividas em José Saramago: \\ entre a verdade e a ficção
}

\author{
Michelle de Oliveira Rolim ${ }^{1}$
}

\begin{abstract}
RESUMO: O objetivo deste trabalho é dar enfoque a escrita autorreferencial e a problemática sobre a verdade e a ficção em textos intimistas. Desta forma, serão ressaltadas as semelhanças entre José Saramago e o personagem $\mathrm{H}$. de Manual de pintura e caligrafia, bem como veremos a possibilidade de o autor ter criado uma versão de si em As Pequenas Memórias, sugerindo, assim, os cruzamentos entre real e imaginário em ambas as escritas.
\end{abstract}

ABSTRACT: This paper aims to focalize the autobiography writing and its problems related to truth and fiction in intimate texts. Therefore, we will emphasize the similarities between José Saramago and his character H. in Manual de pintura $e$ caligrafia, as well as will be verified the possibility of the author has created a version of himself in As Pequenas Memórias, by means of which he would suggest the intersections between real and imaginary in both writings.

PALAVRAS-CHAVE: Autobiografia; Sujeito; Realidade e ficção

KEYWORDS: Autobiography; Individual; Reality and fiction

Como sabemos, há muito José Saramago prometia um texto oficial de natureza autobiográfica, mediante o qual pudesse reunir experiências de parte do passado. No livro As pequenas memórias, o autor discorre sobre a infância e a adolescência, abrindo suas lembranças acerca dos primeiros amores, algumas malévolas criancices, sobre o contato com a pesca, inúmeras mudanças caseiras. São fatos e curiosidades sobre a escola e relações sociais, sobre os quais o leitor obtém conhecimento mediante entrevistas.

${ }^{1}$ Mestranda em Literatura Portuguesa da Universidade Federal Fluminense. Contato: michellelit.portuguesa@hotmail.com 
Nestas memórias, percebemos um Saramago preocupado em mostrar algo além da imagem do escritor consagrado pela comunidade acadêmica internacional, e para isso não faz referências aos compromissos diários, como o faz nos Cadernos de Lanzarote.

Vê-se, portanto, um autor que após tantas escritas do Outro, volve-se para si, criando por ele mesmo a representação de sua personalidade, já que ninguém melhor que o próprio sujeito para reanimar as próprias experiências. Contudo, ao criar uma autobiografia assumidamente incompleta, o autor contraria, de certo modo, a ordem comum de uma escrita intimista cujo início deveria partir de relatos da infância para a vida adulta. Ele burla, pois, a regra cronológica, já que percorre um caminho diferente como afirma em entrevista:

É tão forte a necessidade que tenho de escrever esse livro que se chamará O livro das tentações, que é uma autobiografia, como te disse, mas uma autobiografia um pouco estranha, porque irá só até aos catorze anos e aí pararei porque a idade adulta não me interessa, ao contrário de outras autobiografias, que partem da vida actual e continua, para trás. (SARAMAGO, apud: ARIAS, 2000, p. 82)

Em As Pequenas Memórias, Saramago não faz, antecipadamente, nenhuma referência paratextual quanto ao seu gênero: romance autobiográfico ou memórias efetivamente vividas? Talvez em função da crença na insuficiência das palavras em representar precisamente a realidade, o autor parece esquivar-se de classificar o gênero da própria autobiografia, definindo o livro, modestamente, como "memórias pequenas de quando fui pequeno, simplesmente" (APM, 2006, p. 34). Paira a hipótese de que Saramago reconhece a precariedade da sua representação, já que opta por trazer à tona apenas fragmentos, recordações desordenados de sua história. O fato é que para ele "tudo é autobiografia" (MPC, 1997, p. 9), tal qual cita no Manual de pintura $e$ caligrafia. Diante disso, parece impossivel delimitar textualmente o percurso de uma existência que ainda não se findou.

Neste romance considerado obra inaugural, Saramago revela uma certa inclinação pela escrita autobiográfica, experimentando o discurso 
intimista, como sugere o termo no título "caligrafia", pelas vias do seu personagem. Inúmeros momentos textuais apontam para uma relação de alteridade entre Saramago e o personagem H., o que leva Rebelo a considerar que "o artista plástico tornado escritor tem muito de um heterônimo de José Saramago" (REBELO, 1983, p. 32).

$\mathrm{O}$ protagonista $\mathrm{H}$., desde a singela inicial que o designa, deixa escapar a noção de incompletude do artista em crise entre continuar com suas pinturas repetitivas ou alçar novos voos rumo à representação no âmbito da escrita. Saramago parece incutir em $\mathrm{H}$. marcas de sua própria subjetividade, de modo que o conflito do personagem parece guardar semelhanças com a transição pessoal do próprio autor que, no $M P C$, inicia um novo percurso.

Como relembra Carlos Reis, também em entrevista ao autor, na primeira edição de MPC Saramago dispõe o subtítulo Ensaio de romance (REIS, 1998, p. 13), endossando assim a concepção de que tal obra anuncia uma nova entrada para Saramago no cenário literário. O crítico Horácio Costa, por seu turno, analisa H. como dramatização do próprio Saramago, em busca de uma forma inovadora de ficcionalizar a realidade, já que havia se aventurado apenas na produção de poesia e contos, além do primeiro romance Terra do pecado o qual, segundo ele, "não conta" (SARAMAGO, apud COSTA, 1997, p. 273).

Convém-nos lembrar que o $M P C$ é o primeiro e último romance em que o autor obedece às sinalizações convencionais, já que desde então assume o discurso que mais se aproxima da oralidade, o que é algo inovador na literatura. Com isso, podemos pensar que a repulsa do personagem pelos seus quadros que pinta tradicionalmente corresponde à recusa de Saramago por escrever romances com todas suas sinalizações as quais denomina por "muletas" (MPC, p. 76) ou "sinais de trânsito" (SARAMAGO, apud REIS, 1998, p. 74) sem os quais, para ele, é possível manter a leitura embora esta solicite uma especial atenção.

A escrita do $M P C$ está repleta de alusões a um tipo de relação indissociável entre o real e a ficção, como se esta partisse de fios da 
própria realidade. Igualmente a Saramago que simula a escrita autorreferencial mediante o personagem, $H$. também passa a transcrever as autobiografias de Rousseau e de Robinson. Ele as reescreve a fim de "adestrar a mão, como se estivesse a copiar um quadro. Transcrevendo, copiando, aprendendo a contar uma vida, de mais na primeira pessoa" (MPC, 2. ed., p. 94), treinando, assim, a que doravante escreverá sobre si. Assim, a ação do autor parece estar embutida da prática do personagem num jogo em que se entrelaçam verdade e ficção, de tal modo que o leva a afirmar a indissociabilidade entre ambas:

Não creio que alguém pudesse entender-se neste cruzar de fios, desenredá-los, distinguir os verdadeiros dos falsos e (trabalho ainda mais útil) definir e marcar o grau de falsidade na verdade e de verdade na falsidade. [..] Mas, ao copiar fielmente estas linhas, com honesta intenção de aprender, não noto qualquer diferença, salvo na escrita, entre esta realidade e aquela ficção. (MPC, 2. ed., p. 94-95).

Outra interseção entre Saramago e H. pode ser detectada quando ele, em entrevista a Arias fala sobre sua recusa em incluir o primeiro livro publicado na bibliografia. Como H. que interrompe a pintura por se considerar incapacitado de trazer algo novo à sua carreira de pintor, Saramago também, em dado momento de sua vida, deixa de escrever após a escrita deste primeiro livro, porque se reconhece ainda imaturo como escritor: "com aquele romance e com o seguinte, o que ficou inédito, foi evidente para mim que não tinha muitas coisas para dizer e que, portanto, o melhor era parar de escrever" (ARIAS, 2000, p. 80-1). O episódio em que H. segura o crânio do pai também é uma dramatização de um fato ocorrido com Saramago (SARAMAGO, apud ARIAS, 2000, p. 64), como também o é o fato de $\mathrm{H}$. retratar o homem maduro aos cinqüenta anos em crise diante do seu trabalho, visto que parece simular um fato fictício da vida do próprio autor Saramago que aflora como romancista nessa faixa etária, como sublinha:

[...] aos cinqüenta e oito anos, quando ninguém espera que esse senhor escreva algo (porque se não o escreveu antes, já não o vai 
escrever) publica Levantado do chão [...]. Eu tinha chegado a uma idade em que se começa a dizer adeus, não se chega, despede-se. (SARAMAGO, apud ARIAS, 2000, p. 66-7).

Os dois, portanto, empreendem caminhos estéticos mais audaciosos e é a partir desse ponto de intercessão que podemos, na posição de leitores, fazer as colagens entre um e outro, isso nos leva a intuir que há, de certo modo, muito de autobiografia saramaguiana de forma ficcionalizada no $M P C$.

A escrita torna-se, pois, espaço profícuo para que uma nova construção identitária de Saramago ocorra, propiciando-lhe novas oportunidades e que se redescubra, se reinvente tal qual quando $\mathrm{H}$. alude à escrita como local de renascimento: "O verdadeiro lugar de nascimento é aquele em que, pela primeira vez, lançamos um olhar inteligente sobre nós mesmos". (MPC, 2.ed., p. 96).

Se não for lugar de nascimento, o $M P C$ parece corresponder a um manual de sobrevivência, a partir do qual aquele que se descreve edifica-se, encontra a redenção em meio à peregrinação da narrativa. Redenção ou não, o fato é que o MPC adquire "valor transicional" (COSTA, 1997, p. 277), em vista de se trata de um romance de estreia da fase adulta de Saramago como escritor, à qual se dedica desde então com maior aprimoramento literário.

No texto em que discorre sobre o período formativo da ficção saramaguiana, Costa assinala diversas semelhanças entre o Eu real e o irreal de Saramago, e descreve o personagem H. como uma espécie de desdobramento autoral, devido à notoriedade tardia que o autor alcança sobretudo com Levantado do chão, mas que já podemos notar seu aprimoramento a "romper a distância que o afastara da prosa de ficção por três décadas" (COSTA, 1997, p. 275). Ou seja, ao nascer o "personagem completo" (p. 319), em relação aos das rápidas narrativas anteriores, nasce um novo autor Saramago junto com ele, como cita: "Em MPC Saramago dá a sua primeira demonstração de habilidade sobre a linguagem" (COSTA, 1997, p. 319). O teórico considera, então, que o processo de formação é o traço que com mais acuidade confirma o 
desdobramento autoral no personagem H.:

H., pouco a pouco cura-se a si mesmo através das "vias"que inventa, e conjura seu deserto e volta a pintar, e destaca a acídia e descobre o amor. Em poucas palavras, H. sofre um desabrochar tardio, porém consistente, que emula, talvez não seja de mais dizê-lo, o do romancista José Saramago, já cinqüentão e, entretanto, a ponto de começar sob novas bases a sua carreira literária. (COSTA, 1997, p. 318-9)

Outro ponto de contato entre verdade e ficção encontra-se nas inúmeras paisagens de solidão e evocações ao termo deserto que $\mathrm{H}$. faz. Tais imagens caracterizam também traços marcantes da identidade do próprio autor empírico que, em seu primeiro romance propriamente dito, não consegue criar ainda um personagem totalmente descolado de sua imagem, como Horácio Costa analisa. No tocante ao termo solidão, na entrevista a Arias, Saramago revela mais um grau de parentesco com o personagem H., quando desabafa acerca da profunda necessidade de estar a sós desde criança. Ele afirma trazer este sentimento consigo até a fase adulta, quando sente um desconforto ante muitas pessoas que o leva a se refugiar em caminhadas solitárias para recuperar o equilíbrio interior. Como ele declara,

Essa solidão que para eles se confunde com o abandono, para mim é uma espécie de refúgio. Refugio-me nela como se estivesse num castelo, é como dizer: "Aqui estou, este é o meu terreno."

(SARAMAGO, apud, ARIAS, 2000, p. 33)

Com efeito, o perfil de $\mathrm{H}$. parece estar bastante embaralhado à identidade do autor, todavia cabe-nos ressalvar que, desde o romance Levantado do chão, podemos conferir um Saramago criando personagens mais independentes, diferentes de $\mathrm{H}$. que parece se aliar mais a um alter ego seu. Tais cruzamentos entre criatura e criador, sugerindo também relações estreitas entre realidade e ficção, fazem do MPC uma ficção inaugural, porquanto aqui germinam os romances posteriores, como aponta Horácio Costa:

[...] pode afirmar-se que o livro que começamos a estudar guarda um primeiro, e importante, valor: o de ser uma obra de transição, 
já que nele Saramago se abre pela primeira vez na vida adulta, à prosa de ficção, linguagem que se dedicara maiormente desde então. (COSTA, 1997, p. 273)

O que vemos no Manual é um JS escritor, disfarçado sob a capa do personagem, dramatizando a crise de ser escritor de uma época marcada por escritas neo-realistas, numa busca pela cópia perfeita da realidade. Contudo, a consciência quanto à limitação das palavras em abarcar a realidade o leva a admitir, em certa medida, sua presença na romance autobiográfico ao declarar "logo este primeiro exercício de autobiografia dissimulada me denuncia" (SARAMAGO, 2.ed., p. 106).

Desta forma, podemos inferir que o projeto autobiográfico encontra dificuldade em se realizar plenamente, porque é condicionado pela seleção de recordações feitas na tentativa de reconstituir sua história e dizê-la ininterruptamente. Já que o sujeito é impedido de resgatar com precisão todas as suas memórias, a escrita intimista fica comprometida porque o autobiógrafo pode privilegiar apenas determinados eventos em detrimento de outros.

No que concerne à pretensão compacta de si que o sujeito perscruta na escrita, Umberto Eco explica que toda narrativa possui uma função consoladora que também sempre foi a função suprema do mito: "encontrar uma forma no tumulto da experiência humana" (ECO, 1994, p. 93), motivo pelo qual as pessoas contam histórias e têm contado histórias desde o início dos tempo.

Todavia, não há como o sujeito se encerrar na linguagem, fazendo desta um bloco sólido que se possa abraçar com firmeza. Daí, a dificuldade de o sujeito se reunir inteiramente de forma compacta dentro da história que narra acerca de si mesmo por meio das recordações, a não ser que se trate de uma narração pós-morte, de caráter estritamente fictício, como é o caso do romance machadiano Memórias póstumas de Brás Cubas. Em todos os casos de tentativas de congelar e organizar a realidade um sentimento de angústia parece permear o texto do sujeito que busca a auto-representação de algo inapreensível e é essa natureza inapreensível do passado. 
Tantas palavras escritas desde o principio, tantos traços, tantos sinais, tantas pinturas, tanta necessidade de explicar e entender, e ao mesmo tempo tanta dificuldade porque ainda não acabámos de explicar e ainda não conseguimos entender. (MPC, 2.ed., p. 99-100)

O passado é algo impalpável sobretudo porque, como assinala Rebelo: "Recordar é, no fundo, imaginar e sentir. E imaginar é deformar" (REBELO, 1983, p. 29). A autobusca e a tentativa de prender a realidade dentro da caixa autobiográfica segue, então, uma trajetória sem fim, porque, no momento em que o sujeito chega a alguma ideia de verdade de si, esta se evanesce e cede lugar a lacunas e a novas interrogações que o impulsionam a voltar ao caminho da busca novamente.

Assim sendo, a interpretação que o sujeito faz sobre sua história prejudica a exatidão dos acontecimentos como realmente aconteceram e daí a idéia de que ficção se alia ao real comprometendo a eficácia do projeto autobiográfico, dada a intervenção do imaginário quando da distinção dos eventos.

Como sabemos, as lembranças constituem o mote inicial para o desenvolvimento de qualquer escrita, sobretudo, a autorreferencial, mas para fazer emergir o Eu do passado é necessário que seja evocado o poder criativo da lembrança, da imaginação e, aqui, as fronteiras entre ficção e a realidade se confundem, se misturam.

Em um dos artigos de Românica - Revista de literatura, Paula Mourão capta este malogro do individuo que tenta se comprimir no discurso intimista, ao afirmar que “ao procurar o 'eu' no passado, o sujeito quer reorientar o porvir, autocorrigindo-se ou inflectindo no seu percurso, construindo uma utopia de si que espera poder cumprir. (MOURÃO, 1994, p. 28).

No entanto, essa intenção, em Saramago, não parece corresponder à noção de um empreendimento mal sucedido. O que fica comprometido, pois, é a representação que, sob os enfeites da imaginação, perde a integridade do real para ganhar outra realidade no 
nível da realidade textual. É como se o sujeito cognoscente não apenas criasse a linguagem, mas criasse com a mesma e este poder imaginativo que adentra a realidade e se mistura a ela. Tudo isso é criação e, portanto, ficção. Desta maneira, não seria errôneo se afirmássemos a existência de ficção dentro da autobiografia de Saramago, uma vez que as fronteiras entre ambas as dimensões são vulneráveis a cruzamentos.

Segundo o teórico Philippe Lejeune, a autobiografia se define por "Narrativa retrospectiva em prosa que uma pessoa real faz sobre sua própria existência, sobre a sua vida individual, em especial a história de sua personalidade." (LEJEUNE, 1985, p. 14). Com isso, se no MPC o acordo de ficção se estabelece desde o início, em As Pequenas Memórias não é diferente. Nestas, o pacto autobiográfico, ou o que Eco chama de "narrativa natural" (ECO, 1994, p. 125) é selado com os que possuem algum tipo de conhecimento sobre a vida pessoal do autor José Saramago e sabem de sua promessa em escrever uma autobiografia.

Assim, ele permite que as relações de identidade se estabeleçam conduzindo o leitor ao reconhecimento de dados pessoais coesos a ele no papel de escritor conhecido e consagrado. A este propósito, é conveniente retomar a análise sobre o termo ficção segundo Costa Lima, essa outra dimensão imaginativa produzida em texto de ficções não se opõe à realidade propriamente dita. Ficção não se define, simplesmente, como avesso ao real, ou mentira, porque

O plano da realidade penetra o jogo ficcional [...], porquanto o que nele está se mescla com o que poderia ter havido; o que nele há se combina com o desejo do que estivesse; e que por isso passa a haver e a estar. (LIMA, 1984, p. 195).

Como praticantes da língua, seja a falada ou a escrita em diários, correspondências e autobiografias, o fato é que o leitor é inserido num duplo contexto, porque ao sujeito é dado o privilégio de coabitar um mundo reinventado continuamente pelo poder criativo da palavra, cerne este sobre o qual Bittencourt anuncia: 
Imantada por um poder demiúrgico, a linguagem é capaz de irisar o mundo em cores e facetas sempre cambiantes, oferecendo ao sujeito que fala a possibilidade de uma visão caleidoscópica do real. Modelando e remodelando o Cosmos de múltiplas maneiras, a linguagem permite ao falante perenizar o momentâneo, imobilizar o movediço, atribuir dinamicidade ao que é estático. (BITTENCOURT, 2003, p. 38)

Parece-nos que Fernando Pessoa também se apercebe disso ao afirmar no seu desassossego poético que "os campos são mais verdes no dizer do que no seu verdor. As flores, se forem descritas com frases que as definam no ar da imaginação, terão cores de uma permanência que a vida celular não permite." (PESSOA, 1986, p. 398). Fica assim registrada a interpretação pessoana de que o mundo dos homens e das coisas adquire mais vitalidade quando tocado pelo condão inventivo da palavra.

Conforme explica Lejeune, a autobiografia é o espaço de diálogo do narrador consigo próprio, com suas experiências ditas reais. Nesse sentido, o que distingue a narrativa ficcional autobiográfica da "puramente" autobiográfica é o fato de a primeira produzir um "outro mundo" imaginário, ao passo que a última refere-se a uma "realidade" anterior e exterior ao texto vivida pelo autor. Mas até que ponto não existem experiências reais embutidas em discursos fictícios de primeira pessoa como é o caso do Manual?

Levando em consideração a possibilidade de haver fatos romanceados em $A P M$, vemos a literatura como aquela que confere ao indivíduo um espaço de autonomia para a expressão de sua unidade na diversidade, capaz de concentrar as atenções apenas nas questões do sujeito, como vemos em produções autobiográficas, em que a escrita é o lugar de pura afirmação do sujeito e das interpretações que ele faz acerca de tudo.

Vemos, portanto, que um outro Eu se constitui na escrita de maneira fragmentada, pois não é a figura cartesiana e centrada que poderia mirar num espelho comum. Com efeito, é a linguagem que promove a visibilidade de tais estilhaços, enquanto o sujeito busca reproduzir debalde o real e a própria imagem, num ludismo verbal que 
só nos leva a crer que ficção e fatos são, na perspectiva da representação, indissociáveis.

\section{REFERÊNCIAS BIBLIOGRÁFICAS:}

BARTHES, Roland. O rumor da lingua. São Paulo: Brasiliense, 1988.

BITTENCOURT, Terezinha. As propriedades essenciais da linguagem. In. Revista Confluência. Instituto de Língua Portuguesa do Liceu Literário Português, Rio de Janeiro. N. 25 e 26., p. 36-54, $1^{\circ}$ e $2^{\circ}$ semestre de 2003.

COSTA, Horácio. José Saramago: o periodo formativo. Lisboa: Ed. Caminho, 1997.

ECO, Umberto. O nome da rosa. Rio de Janeiro: Record, 1986.

_. Seis passeios pelos bosques da ficção. $2^{\mathrm{a}}$ ed. São Paulo: Companhia das Letras, 1994.

LEJEUNE, Philippe. Le pacte autobiographique. Paris: Seuil, 1985.

LIMA, Luis Costa. Documento e ficção, In. Sociedade e discurso ficcional. Rio de Janeiro: Guanabara, 1984.

MOURÃO, Paula. O secreto e o real - Caminhos contemporâneos da Autobiografia e outros artigos intimistas. Românica - Revista de Literatura 3. Faculdade de Letras de Lisboa, 1994.

PESSOA, Fernando. O livro do desassossego. São Paulo: Brasiliense, 1986.

REBELO, Luís de Sousa. Os rumos da ficção de José Saramago. Prefácio à $2^{\mathrm{a}}$ edição de Manual de Pintura e Caligrafia. Lisboa: Caminho, 1983. REIS, Carlos. Diálogos com José Saramago. Lisboa: Caminho, 1998.

SARAMAGO, José. Cadernos de Lanzarote I. Lisboa: Caminho, 1997. - Manual de pintura e caligrafia. 2.ed. São Paulo: Companhia das Letras, 1998. As Pequenas Memórias. São Paulo: Companhia das Letras, 2006. , ARIAS, Juan. José Saramago: O amor possivel. Lisboa: Dom Quixote, 2000. 